\title{
New Sri Lankan Crown Rump Length Chart
}

\author{
Kelum Saranga Jayasinghe ${ }^{1 *}$, Sunil Kulatunga ${ }^{2}$, Udugamage Don Puspananda Ratnasiri² \\ ${ }^{1}$ Colombo South Teaching Hospital, Kalubowila, Sri Lanka \\ ${ }^{2}$ Castle Street Hospital for Women, Colombo, Sri Lanka \\ Email: *kelumj@yahoo.com
}

How to cite this paper: Jayasinghe, K.S., Kulatunga, S. and Ratnasiri, U.D.P. (2022) New Sri Lankan Crown Rump Length Chart. Open Journal of Obstetrics and Gynecology, 12, 11-24.

https://doi.org/10.4236/ojog.2022.121002

Received: December 2, 2021

Accepted: January 10, 2022

Published: January 13, 2022

Copyright (C) 2022 by author(s) and Scientific Research Publishing Inc. This work is licensed under the Creative Commons Attribution International License (CC BY 4.0).

http://creativecommons.org/licenses/by/4.0/

(c) (i) Open Access

\begin{abstract}
Introduction Accurate pregnancy dating is important for many aspects of obstetric care at individual level as well as population level. Traditionally, pregnancy dating has done by adding 9 months and 7 days to the last menstrual period (LMP) using Naegele's formula. Determination of gestational age by ultrasound is more precise. Most commonly used parameters are mean sac diameter, gestation sac volume, crown-rump length (CRL), biparietal diameter (BPD), head circumference (HC) and femur length (FL). After 24 weeks, gestational age cannot be accurately determined by ultrasound scans. The biological variability of CRL is small and growth is very rapid. There are many factors that can affect CRL such as measurement errors, differences in growth rates between individuals, fetal sex and maternal conditions such as diabetes mellitus. A correctly performed measurement of CRL is the most accurate way of estimating the gestational age in early pregnancy from 8 weeks to 13 weeks +6 days. Objectives Our study aims were to prepare a new Crown Rump Length chart with Sri Lankan population data and to compare new CRL chart with existing intergrowth CRL chart. Method Prospective observational study with recruitment of subjects by Quota sampling technique was carried out from April 2015 to March 2016. Spontaneously conceived uncomplicated singleton pregnancies with normal Body Mass Index (BMI) $18.5-23 \mathrm{~kg} / \mathrm{m}^{2}$ were recruited at the time of registration to antenatal care. Consenting woman with known LMP with regular cycles in preceding 3 months were undergone ultrasound examination only once at gestational age (GA) ranging from 8 weeks to 13 weeks +6 days. If ultrasound dating was different from LMP dating by more than 5 days in pregnancies with POA less than 9 weeks and dating differences more than 7 days in pregnancies between 9 weeks and 14 weeks were excluded. Pregnancies complicated with uncertain viability, congenital anomalies and spontaneous miscarriage were excluded from statistical analysis. Data collection done with pre-tested interviewer administered form and analysis was carried out using the Statistical Package for Social Sciences (SPSS) version 21. Results A total of 653 subjects were recruited for the study
\end{abstract}


and 557 turned up for ultrasound dating assessment. Dating discrepancy and multiple pregnancies excluded 31 subjects, uncertain viability and spontaneous miscarriage excluded 15 subjects resulting 511 subjects for final statistical analysis. The mean CRL increased with GA almost linearly from day 56 to 97 . Conclusions We have produced new CRL chart based on Sri Lankan data and it can be used for clinical practice in Sri Lanka. There is no statistically significant difference between our CRL chart and intergrowth CRL chart.

\section{Keywords}

Crown Rump Length, Gestational Age, Pregnancy Dating, Ultrasound Scan Dating

\section{Introduction}

Accurate pregnancy dating is important for many aspects of obstetric care at individual level and population level. At individual level dating needed for effective screening for chromosomal anomalies, reducing the pregnancies wrongly labeled as pre-term or post-term therefore minimizing unnecessary interventions. At population level, it is important for resource allocation in above mention settings and it will reduce health care cost due to avoidance of unwanted interventions to the pregnancy.

Traditionally pregnancy dating has done by adding 9 months and 7 days to the last menstrual period (LMP) using Naegele's formula. The LMP is unreliable if the date of the LMP is not accurately known, menstrual cycle is not 28 days long, menstrual cycle is irregular, woman has only stopped taking the combined oral contraceptive pill within the last 3 months, woman has bled in early pregnancy, and woman is breast feeding or has been pregnant in the preceding $3-6$ months.

Determination of gestational age by ultrasound is more precise. Several ultrasound parameters have been used to estimate gestational age. The most commonly used are mean sac diameter, gestation sac volume, crown-rump length (CRL), head circumference (HC), biparietal diameter (BPD) and femur length (FL). After 24 weeks, gestational age cannot be accurately determined by ultrasound scans [1].

Dating by CRL more reliable between 7 weeks to 12 weeks, however between 13 weeks to 15 weeks ultrasound dating can be less accurate as a result of flexion of the fetus. This will make measurement of CRL difficult. During this period dating by measurements of BPD or HC may also be inaccurate. Pregnancy dating errors by ultrasound measurements are smaller than dating calculated with last menstrual period. Pregnancies with assisted reproduction, where the exact date of conception was known dating error for both ultrasound and LMP can be calculated efficiently. Based on these studies, routine ultrasound dating errors distributed normally with standard deviation (SD) of \pm 4 days. The $95 \%$ confi- 
dence interval ranges from -8 days to +8 days. Although dating error with LMP heavily skewed positively towards overestimation where $95 \%$ confidence interval recorded as -9 days to +27 days [2].

The biological variability of CRL is small and growth is very rapid. However, there are still a number of factors that can affect the size of an early embryo such as measurement errors, differences in growth rates between individuals, fetal sex and maternal conditions such as diabetes mellitus. A correctly performed CRL measurement is therefore more accurate than the biparietal diameter in dating a pregnancy. Dating by CRL regarded as current best practice [1].

Commonly used CRL charts produced by Robinson and Hadlock predominantly included Caucasian population [3] [4] [5]. Pexsters et al. suggested the need for development of CRL charts for different population with different ethnic and socioeconomic backgrounds in order to minimize errors due to demographic characteristics of the population. They further suggested unavailability of such charts can produce dating errors which can lead to unnecessary interventions and adverse perinatal outcomes [6].

Widely accepted initial studies were done more than twenty five years ago by Robinson and Hadlock. Methodological differences and changes in technology used in ultrasound scanners in the past and today's practice justify the need of critical review of CRL charts in relation to accuracy in pregnancy dating. This concern was addressed by a systematic review of charts by Napolitano et al. in 2014 [7]. The analysis included 29 studies (over 11,000 pregnancies) from 1975 to 2011. Conclusion of the analysis was four studies conducted by Robinson [3] [4], Sahota [8], McLennan [9], Verburg [10] fulfill most of the quality criteria and they lead to minimal differences in GA estimation by CRL.

In 1987 inaccuracies in dating using published CRL charts were noted among patients with infertility treatment. Exact date of ovulation was aware in these patients and dating by CRL found to be different than in vivo pregnancies. MacGregor et al. studied seventy two patients with known ovulation dates and suggested there was underestimation of gestation age by using Robinson CRL chart [11].

Assessment of accurateness of dating formula using CRL was difficult task as it necessitates an independent gold standard for estimation of gestational age. Studies using in vitro fertilization [12] [13] with known dates of embryo transfer used to formulate CRL charts but problems of such approach were pregnancies using IVF technique not biologically comparable to natural spontaneously conceived pregnancies. IVF pregnancies associated with high rate of congenital anomalies as well as carries higher perinatal risks [14] [15] [16]. Therefore, it is wise to assume early growth of the embryo and fetus also differs among spontaneously conceived pregnancies and IVF pregnancies.

In 2014 Papageorghiou et al. (Intergrowth-2 $1^{\text {st }}$ project) produced first international standards for ultrasound dating based on CRL measurement. In this study population recruited from eight different countries and mainly included urban population between 9 weeks and 13 weeks +6 days of gestation who met strict 
eligibility criteria. Adherence to strict protocols and quality assurance systems were mandatory prior to CRL measurements. Follow up arranged for all subjects during antenatal, intrapartum and postpartum period. Congenital anomalies, pregnancies with complications, fetal deaths and neonatal deaths were excluded. Final assessment included data from 4265 women [17]. Study demonstrated the differences between Robinson [4], Verburg [10] and Intergrowth-21 $1^{\text {st }}$ [17], in estimating GA based on CRL measurements were small. These small dating differences between studies are unlikely to produce significant differences clinically. Up to CRL 80 millimeters difference between gestation age estimation by both Robinson and Verburg et al. was \pm 1 day. The Intergrowth- $21^{\text {st }}$ findings were also in line with Robinson up to CRL $80 \mathrm{~mm}$. The Intergrowth- $21^{\text {st }}$ and Verburg et al. then exceed the difference to more than 2 days when CRL $>85$ $\mathrm{mm}$. These remarkable similarities between studies done in different settings and different eras suggested early fetal growth assessed by CRL measurements appears to be uniform over time and between ethnicities after achieving adequate standard of nutrition, health and socioeconomic condition.

Our study aims were to prepare a new CRL chart based on Sri Lankan population data and compare it with international CRL chart (Intergrowth-2 $1^{\text {st }}$ ). Locally produced CRL chart minimize errors due to demographic characteristics of the Sri Lankan population.

\section{Objectives}

To construct a new fetal crown-rump length (CRL) chart for early pregnancy dating in Sri Lanka.

To compare new CRL chart with existing Intergrowth- $21^{\text {st }} \mathrm{CRL}$ chart.

\section{Study Method}

\subsection{Study Population and Recruitment}

The study was carried out as a prospective observational study conducted at the ward $9 \& 10$, Castle street hospital for women (CSHW), Colombo 08 and ward 10 \& 17, Colombo South Teaching Hospital (CSTH), Kalubowila. Recruitment of subjects by Quota sampling technique was carried out from April 2015 to March 2016.

Spontaneously conceived subjects with normal Body Mass Index (BMI) 18.5 $23 \mathrm{~kg} / \mathrm{m}^{2}$ were recruited at the time of booking visit prospectively. Consenting woman with known LMP with regular cycles in preceding three months were assigned with appointment for ultrasound assessment of CRL by author specifically for the purpose of study. Assessment gestation ages assign in a manner that they were ranging from 8 weeks to 13 weeks +6 days. Each subject was assign for only one ultrasound scan to avoid serial measurement of same fetus. Pregnancies were dated in accordance with menstrual dates.

At the time of recruitment to the study following exclusion criteria were empowered: uncertain LMP; irregular menstrual cycle; usage of hormonal contra- 
ception within 3 months of LMP; maternal medications and maternal disorders with known impact on fetal growth (hypertension, diabetes mellitus, renal disease,); previous history of intra uterine death (IUD) or fetal growth restriction (FGR); and multiple pregnancies. If ultrasound dating were different from LMP dating by more than 5 days in pregnancies with period of gestation (POG) less than 9 weeks and dating difference more than 7 days in pregnancies between 9 and 14 weeks were excluded [18]. Pregnancies complicated with congenital anomalies, uncertain viability and spontaneous miscarriage at initial ultrasound assessment or subsequently were excluded at the time of statistical analysis.

\subsection{Sample Size}

Calculation of suitable sample size for development of centile charts is not an easy task. Greater precision of centiles can be achieved by recruiting larger sample size. The standard error (SE) of the 100th centile $\left(\mathrm{C}_{100}\right)$ can be expressed as $\mathrm{SE}\left(\mathrm{C}_{100}\right)=\sqrt{\left[\left(1+Z^{2} / 2\right) / n\right]} \quad n=$ number of study subjects, $Z$ score taken from standard normal distribution [19]. This disregards errors with inappropriate modeling in relation to GA. Thus the width of, for example a $95 \%$ confidence interval for the 90th centile (for which $z=1.282$ ) is

$\pm 1.96 \mathrm{SE}\left(\mathrm{C}_{90}\right)=2.65 \mathrm{SD} / \sqrt{n}$ which for $n=1000$ is $\pm 0.08 \mathrm{SD}$ and for $n=500$ is \pm 0.12 SD. More extreme centiles are less precisely estimated [20] [21].

There were 42 data collection points (e.g. $8 \mathrm{w}+0 \mathrm{~d}, 8 \mathrm{w}+1 \mathrm{~d}, 8 \mathrm{w}+2 \mathrm{~d} . . .13 \mathrm{w}+6 \mathrm{~d}$ ) in this study. Using quota sampling recruited 653 subjects with minimum of 10 subjects to each data collection point. Final statistical analysis included 511 subjects.

\subsection{Concerns in Measuring CRL}

The very early embryo is unflexed. CRL measurements taken between 5 and 7 weeks are inaccurate because of either the full length of the embryo has not been obtained (this will produce an underestimated CRL) or the end-points of the embryo have not been clearly identified as separate from the closely adjacent yolk sac or the wall of the gestation sac and one or both have been included in the measurement (this will produce an overestimated CRL).

Although it becomes much easier to identify the end-points of the embryo after 7 weeks, it remains just as important to ensure that imaging the maximum length of the embryo before taking the measurements. The CRL should be measured from three different images and the measurements should agree to within 3 $\mathrm{mm}$ in the embryo and $5 \mathrm{~mm}$ in the fetus. Once the fetal spine can be easily identified, that is from about 9 weeks, this should be used as a guide in assessing true fetal length. The aim is to examine the fetus with the full length of its spine positioned directly anteriorly or posteriorly, thereby enabling to assess any degree of flexion.

When linear calipers are used flexion of fetal spine by any degree will result underestimation of CRL. Estimation of degree of flexion is difficult with lateral flexion. When performing trans-abdominal scans changing the angle of probe in relation to maternal abdomen might help to bring fetal spine into more posterior 
or anterior position. This simple alteration of probe placement will make CRL measurement more accurate as far as possible [1].

\subsection{Procedure}

After recruitment of subjects at booking visit they were given an appointment for dating ultrasound scan performed by author using either trans-abdominal or trans-vaginal probe for B-mode imaging. The trans-vaginal route used as preferred method for assessing gestational age by CRL until 9 weeks of gestation. After that trans-abdominal route is used [1]. CRL measured either using Noblus, Hitachi Aloka Medical Limited, Tokyo, Japan ultrasound diagnostic scanner or Logiq F series, GE healthcare, Germany ultrasound scanner.

Neutral position of the fetus (between chin and chest visible amniotic fluid pocket) used to measure CRL. Measurements were taken along the longest axis of the fetus and fetal limbs and yolk sac excluded from the measurements. Measurements were taken after satisfactory magnification (Screen almost filled by the fetus); in mid-sagittal section with correctly placed calipers (Caliper intersections were placed at outer borders of skin of head and rump). Three measurements of each fetus were taken. Statistical analyses done with mean CRL.

\subsection{Data Collection}

Age, Parity, BMI, Education level, Employment, Monthly income, LRMP, POA and CRL recorded on a pre-tested interviewer administered data collection form (Annex 1) and was saved on to an ongoing electronic data base (Microsoft Excel).

\subsection{Data Analysis}

Statistical analysis was carried out using the Statistical Package for Social Sciences (SPSS) version 21. For each gestation age mean CRL and standard deviation (SD) estimated. Calculation of centiles using mean and SD not a difficult task it can be done using following statistical formula:

$$
\mathrm{P}^{\text {th }} \text { centile }=\text { mean } \mathrm{CRL} \pm(Z \times \mathrm{SD})
$$

From the normal charts $Z$ ( $Z$ score) were taken to particular centile e.g. $Z=$

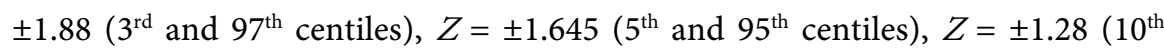
and $90^{\text {th }}$ centiles) respectively. Here we assume data for each GA comes from a normally distributed population [20] [21].

\subsection{Ethical Considerations}

Ethical clearance for the study was obtained from Ethical Review Committee, Faculty of Medicine, University of Colombo (Annex 2). Informed written consent obtained from subjects before recruitment (Annex 3). All participants were given contact details of the investigators and the contact details of the Ethics Review Committee in case they need to clarify any doubts about the study.

Name of the participants were not obtained for the data extraction process \& data kept under lock \& key. Computerized data kept under password protection 
with the principal investigator. All data collection forms will be destroying six months after study. Data obtained through the study shall only be divulged at suitable scientific fora. Strict confidentiality of the collected data guaranteed and only grouped data will be presented and discussed.

\section{Results}

A total of 653 subjects were recruited for the study and 557 turned up for ultrasound dating assessment. Dating discrepancy and multiple pregnancies excluded 31 subjects, uncertain viability and spontaneous miscarriage excluded 15 subjects resulting 511 subjects for final statistical analysis (Figure 1).

Age range of subjects was 18 years to 41 years and the median was 28 years. Median gestational age of ultrasound examination according to LMP was 11 weeks +1 day (range 8 weeks to 13 weeks +6 days).

Two hundred fourteen subjects (41.9\%) were nulliparous. Majority $72.4 \%(\mathrm{n}=$ 370) are Sinhalese; basic characteristics of the study population are given in Table 1.

Table 1. Characteristics of subjects $(n=511)$.

\begin{tabular}{|c|c|c|c|}
\hline \multicolumn{2}{|c|}{ Characteristics } & \multirow{2}{*}{$\begin{array}{c}\text { No of Subjects } \\
370\end{array}$} & \multirow{2}{*}{$\begin{array}{c}\text { Percentage } \\
72.4 \%\end{array}$} \\
\hline \multirow{4}{*}{ Ethnicity } & Sinhala & & \\
\hline & Tamil & 77 & $15.1 \%$ \\
\hline & Muslim & 52 & $10.2 \%$ \\
\hline & Other & 12 & $2.3 \%$ \\
\hline \multirow{6}{*}{ Age (years) } & $<20$ & 13 & $2.5 \%$ \\
\hline & $21-25$ & 126 & $24.7 \%$ \\
\hline & $26-30$ & 162 & $31.7 \%$ \\
\hline & $31-35$ & 108 & $21.1 \%$ \\
\hline & $36-40$ & 93 & $18.2 \%$ \\
\hline & $>40$ & 9 & $1.8 \%$ \\
\hline \multirow{5}{*}{$\begin{array}{c}\text { Monthly } \\
\text { Income (Rs) }\end{array}$} & $<25,000$ & 123 & $24.1 \%$ \\
\hline & $25,001-50,000$ & 286 & $56.0 \%$ \\
\hline & $50,001-75,000$ & 75 & $14.7 \%$ \\
\hline & $75,001-100,000$ & 18 & $3.5 \%$ \\
\hline & $>100,000$ & 9 & $1.7 \%$ \\
\hline \multirow{6}{*}{$\begin{array}{l}\text { Education } \\
\text { Level }\end{array}$} & No Schooling & 7 & $1.3 \%$ \\
\hline & Grade 1 - 5 & 11 & $2.2 \%$ \\
\hline & Grade $6-10$ & 24 & $4.7 \%$ \\
\hline & $O / L$ & 196 & $38.4 \%$ \\
\hline & $A / L$ & 247 & $48.3 \%$ \\
\hline & Higher Education & 26 & $5.1 \%$ \\
\hline
\end{tabular}

$\mathrm{A} / \mathrm{L}=$ GCE Advanced Level, $\mathrm{O} / \mathrm{L}=$ GCE Ordinary Level, Rs = Rupees. 


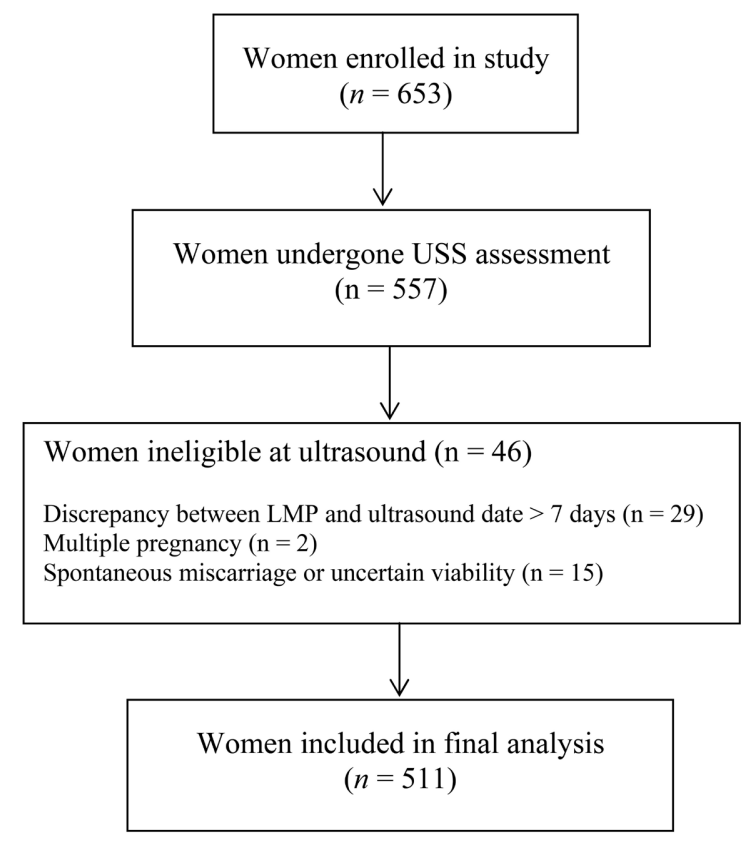

Figure 1. Flow diagram of study recruitment process.

Among study subjects $48.3 \%$ educated up to advanced level (A/L). Fifty six present of study subjects $(n=286)$ having monthly income between twenty five thousand to fifty thousand rupees.

Mean fetal size increased with gestational age between day 56 and day 97. Increase of SD roughly linear between day 56 to day 84 thereafter declining (Table 2, Figure 2). Calculation of centiles using mean and SD not a difficult task it can be done using following statistical formula:

$$
\mathrm{P}^{\text {th }} \text { centile }=\text { mean } \mathrm{CRL} \pm(Z \times \mathrm{SD})
$$

where $Z$ ( $Z$ score) is the normal equivalent deviate corresponding to a particular centile, e.g. $Z= \pm 1.88$ (3rd and 97th centiles), $Z= \pm 1.645$ (5th and 95th centiles), $Z= \pm 1.28$ (10th and 90th centiles) respectively. Using above formula for day 56 in our study $3^{\text {rd }}, 5^{\text {th }}, 10^{\text {th }}, 50^{\text {th }}, 90^{\text {th }}, 95^{\text {th }}$ and $97^{\text {th }}$ centile values in millimeter are $14.74,14.95,15.2,16.43,17.58,17.91$ and 18.12 respectively.

Crown-rump length $(\mathrm{mm})$ pattern change with gestational age in days with the best fit linear and quadratic regression model shows in Figure 2. Quadratic regression minimizes outliers in comparison to linear regression method in our study.

After plotting mean CRL and mean \pm 2 SD against period of gestation in weeks the curve showed almost linear increase in mean CRL with period of gestation. Minimum SD $2.32 \mathrm{~mm}$ observed at 8 weeks of POG and maximum SD $6.62 \mathrm{~mm}$ observed at 12 weeks of POG (Figure 3).

Comparison with Intergrowth- $21^{\text {st }}$ chart and our new CRL chart showed a maximum difference in mean CRL of $2.95 \mathrm{~mm}$ at 11 weeks of POG and minimum difference $0.85 \mathrm{~mm}$ at 10 weeks of POG (Table 3, Figure 4). Our sample $\mathrm{SD}$ was lower than that of intergrowth for all gestational ages. 
Table 2. Crown-rump length (CRL) according to gestational age.

\begin{tabular}{|c|c|c|c|c|c|}
\hline $\begin{array}{c}\text { Gestational Age } \\
\text { (Days) }\end{array}$ & $\begin{array}{l}\text { Mean CRL } \\
\quad(\mathrm{mm})\end{array}$ & SD & $\begin{array}{c}\text { Gestational Age } \\
\text { (Days) }\end{array}$ & $\begin{array}{l}\text { Mean CRL } \\
\quad(\mathrm{mm})\end{array}$ & SD \\
\hline 56 & 16.43 & 0.90 & 77 & 40.68 & 3.15 \\
\hline 57 & 17.11 & 0.89 & 78 & 43.29 & 3.37 \\
\hline 58 & 17.87 & 1.21 & 79 & 44.39 & 3.33 \\
\hline 59 & 18.73 & 1.14 & 80 & 45.62 & 2.76 \\
\hline 60 & 20.00 & 1.89 & 81 & 47.38 & 3.67 \\
\hline 61 & 20.79 & 1.61 & 82 & 50.72 & 5.12 \\
\hline 62 & 21.96 & 1.99 & 83 & 51.05 & 5.61 \\
\hline 63 & 23.01 & 2.07 & 84 & 53.80 & 7.07 \\
\hline 64 & 23.87 & 2.13 & 85 & 55.31 & 5.46 \\
\hline 65 & 25.64 & 1.88 & 86 & 56.50 & 6.13 \\
\hline 66 & 26.24 & 1.96 & 87 & 59.87 & 5.08 \\
\hline 67 & 27.41 & 1.62 & 88 & 60.45 & 5.52 \\
\hline 68 & 28.29 & 1.66 & 89 & 62.45 & 4.55 \\
\hline 69 & 29.81 & 1.94 & 90 & 64.69 & 6.35 \\
\hline 70 & 31.00 & 1.71 & 91 & 65.42 & 5.45 \\
\hline 71 & 33.19 & 2.49 & 92 & 68.51 & 6.48 \\
\hline 72 & 34.55 & 3.04 & 93 & 70.69 & 4.62 \\
\hline 73 & 34.65 & 3.06 & 94 & 71.31 & 5.32 \\
\hline 74 & 36.43 & 2.22 & 95 & 74.52 & 3.12 \\
\hline 75 & 38.68 & 3.82 & 96 & 75.60 & 4.18 \\
\hline 76 & 40.26 & 3.89 & 97 & 77.24 & 2.78 \\
\hline
\end{tabular}

$\mathrm{CRL}=$ Crown Rump Length, $\mathrm{SD}=$ Standard Deviation.

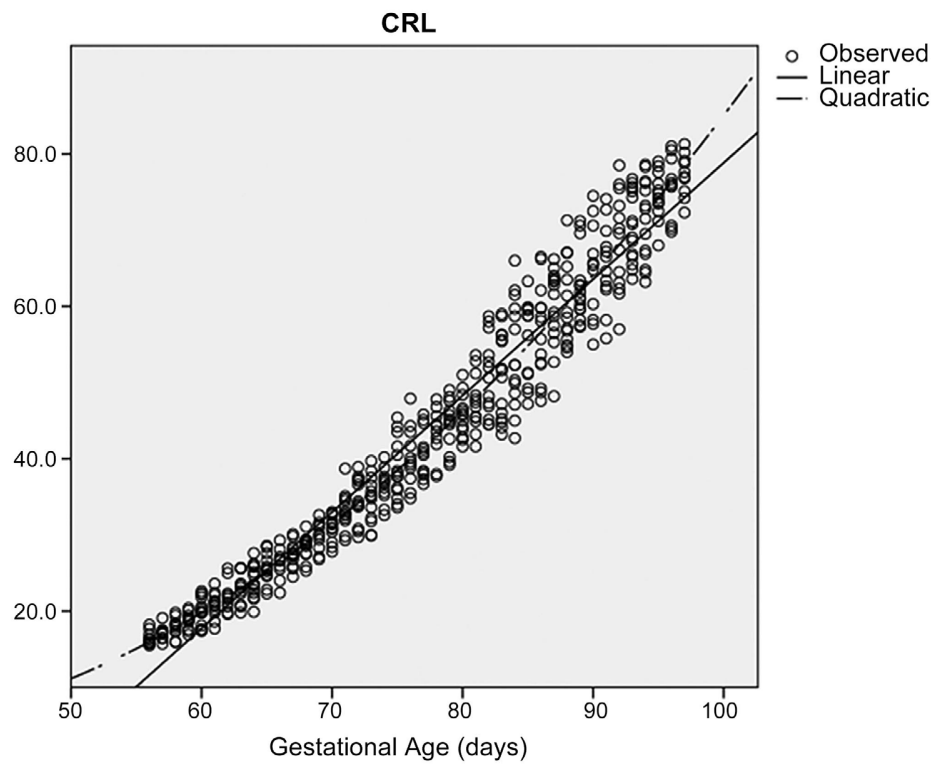

Figure 2. Observed relationship between CRL ( $\mathrm{mm}$ ) and Gestational Age (days) with the best fit linear and quadratic regression models. 


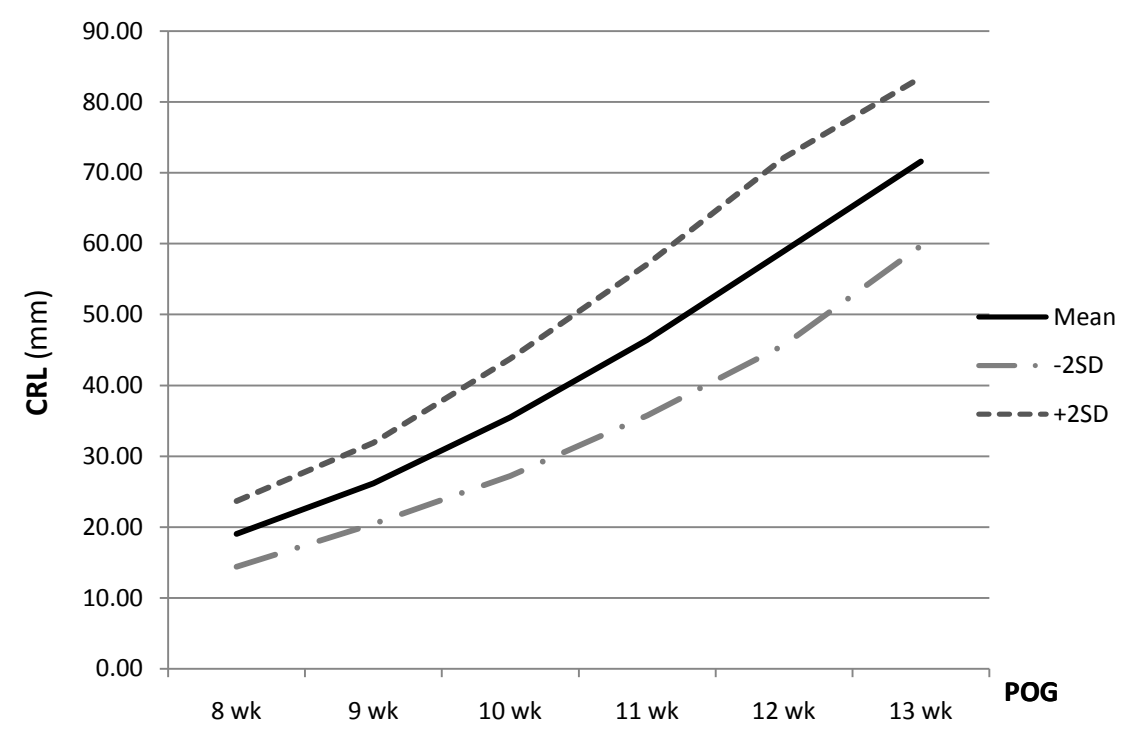

Figure 3. New Sri Lankan CRL chart with mean \pm 2 SD in relation to POG (Wk). CRL $=$ Crown Rump Length, POG $=$ Period of Gestation, $\mathrm{SD}=$ Standard Deviation, $\mathrm{WK}=$ Weeks.

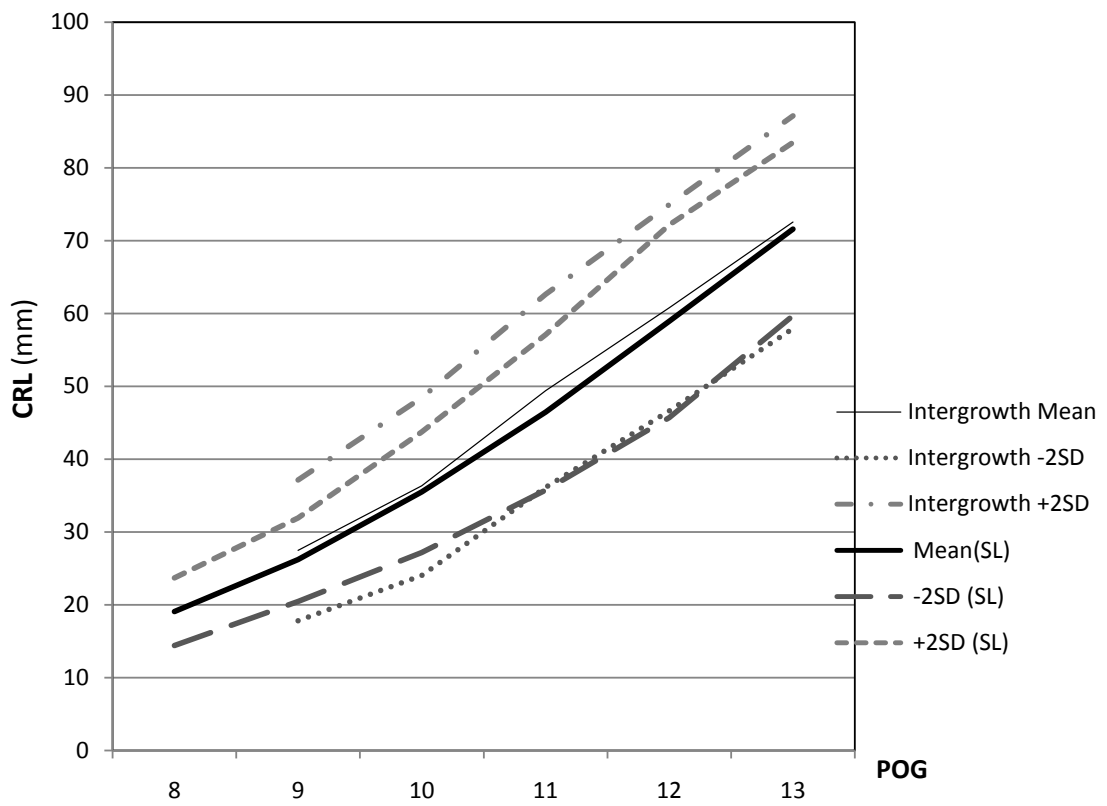

Figure 4. Comparison between new Sri Lankan CRL chart with Intergrowth-2 $1^{\text {st }}$ chart. $\mathrm{CRL}=$ Crown Rump Length, $\mathrm{POG}=$ Period of Gestation, $\mathrm{SD}=$ Standard Deviation, $\mathrm{SL}$ $=$ Sri Lanka.

In both studies mean CRL increased with gestation almost linearly and there were small difference between two sample means. Our sample mean $+2 \mathrm{SD}$ were lower than intergrowth mean $+2 \mathrm{SD}$ at all gestation ages. Mean $-2 \mathrm{SD}$ of our sample initially less than intergrowth mean - 2SD but after 11 weeks both are almost in line. Using independent sample paired $\mathrm{T}$ test there was no statistically significant difference between two sample means ( $\mathrm{t}$-value -0.135 , the $\mathrm{p}$-value 0.447 ) and Standard deviations ( $\mathrm{t}$-value -1.756 , $\mathrm{p}$-value 0.585 ) of two studies. 
Table 3. Comparison between our new study and Intergrowth $-21^{\text {st }}$ project mean CRL and SD according to gestational age.

\begin{tabular}{ccc}
\hline Weeks & Mean \pm SD (SL) & Mean \pm SD (Intergrowth) \\
\hline 8 & $19.06 \pm 2.32$ & \\
9 & $26.19 \pm 2.87$ & $27.47 \pm 4.83$ \\
10 & $35.48 \pm 4.14$ & $36.33 \pm 6.10$ \\
11 & $46.44 \pm 5.34$ & $49.39 \pm 6.62$ \\
12 & $58.95 \pm 6.62$ & $60.78 \pm 7.07$ \\
13 & $71.59 \pm 5.95$ & $72.53 \pm 7.29$ \\
\hline
\end{tabular}

$\mathrm{SD}=$ Standard Deviation, $\mathrm{SL}=$ Sri Lanka

\section{Discussion}

We have developed new CRL chart based on Sri Lankan population data for early pregnancy dating in Sri Lanka. New CRL chart correlate well with first internationally produced CRL chart by Intergrowth $-21^{\text {st }}$ project.

There are two schools of thoughts among experts regarding development of centile charts. Some of them believe in development of centiles with serial assessment of same fetus. CRL values obtain from serial measurements of same fetus highly correlated to each other therefore not suitable for development of fetal size charts. In studies with serial measurements effective sample size more related to number of fetuses than total number of observations [20]. More widely accepted approach is using single fetus only once for measurement of CRL in order to minimize this. Therefore in our study we measured CRL only once from single fetus.

Some studies e.g. Pexsters et al. [6] done using routinely collected data therefore the possibility of inclusion of multiple CRL measurement from same fetus cannot be excluded. When there is clinical indication fetuses are measured repeatedly. Therefore routinely collected data analyzed in retrospective manner is not justified for development of centile charts. We have recruited our sample in prospective manner purposefully to avoid this.

Next methodological strength was correct sampling process. Quota sampling technique with predefined minimum number of subjects for each data collection point avoided under-representation of subjects in any given gestation age. Some studies used to exclude fetus found to be large or small for dates in later gestation or after birth. This should not be done unless there is a congenital abnormality in the fetus. Our study sample selected from healthy women. Predefined sample selection criteria and study protocol used for recruitment helps us to achieve representative sample of normal fetuses. Because of all above reasons we believe selected sample of subjects in our study had the optimal potential for ideal fetal growth. This approach permitted creation of Sri Lankan CRL chart with minimal bias. Our study sample from different ethnic backgrounds percentage is similar to national figures provided by department of census and statistics 
Sri Lanka [22]. This will help to make the findings as generalizable as possible in Sri Lankan setting. Ultrasound assessments were done by single operator and help to minimize inter-observer errors.

In 2014, Papageorghiou et al. (Intergrowth-2 $1^{\text {st }}$ project) produced first international standards for ultrasound dating based on CRL measurement. In this study population recruited from eight different countries and mainly included urban population between $9+0$ and $13+6$ weeks of gestation who met strict eligibility criteria. Final assessment included data from 4265 women [17]. Study demonstrated the differences between Robinson [4], Verburg [10] and Intergrowth-2 $1^{\text {st }}$ [17], in estimating GA based on CRL measurements were small. These small dating differences between studies are unlikely to produce significant differences clinically. Up to CRL 80 millimeters difference between gestation age estimation by both Robinson and Verburg et al. was \pm 1 day. The Intergrowth- $21^{\text {st }}$ findings were also in line with Robinson up to CRL $80 \mathrm{~mm}$. The Intergrowth- $21^{\text {st }}$ and Verburg et al. then exceed the difference to more than 2 days when CRL $>85$ $\mathrm{mm}$. These remarkable similarities between studies done in different settings and different eras suggesting that early linear fetal growth measured with CRL seems to be uniform both over time and among ethnicities after achieving adequate standard of nutrition, health and socioeconomic condition.

Our study in comparison with Intergrowth- $21^{\text {st }}$ chart showed a maximum difference in mean CRL of $2.95 \mathrm{~mm}$ at 11 weeks of POG and minimum difference $0.85 \mathrm{~mm}$ at 10 weeks of POG. In both studies mean CRL increased with gestation almost linearly and there were small difference between two sample means. SD and mean +2 SD of our sample were lower than that of intergrowth for all gestational ages. Mean -2 SD of our sample initially less than intergrowth mean -2 SD but after 11 weeks both are almost in line. Therefore dispersion of data set was smaller in our study. Using independent sample paired $\mathrm{T}$ test there was no statistically significant difference between two sample means ( $t$-value -0.135 , the $\mathrm{p}$-value 0.447 ) and Standard deviations ( $\mathrm{t}$-value -1.756 , $\mathrm{p}$-value $0.585)$ of two studies.

\section{Limitations}

Our study included 511 subjects in final statistical analysis. This size of sample selected because of feasibility to complete the study in given time frame. If we recruited larger sample size the precision of chart will be high. In comparison to the national figures from department of census and statistics 2012 our sample differs from education attainment this difference may be due to sampling done in Colombo district. Majority $48.3 \%$ educated up to advanced level (A/L) where as in national level $37.5 \%$ educated up to grade 6 to 10 [22].

Our study included pregnancies between 8 weeks to 13 weeks +6 days therefore the curve derived by these data cannot use to predict CRL outside this POG and it is one of limitation in our study. Before generalization our own Sri Lankan CRL chat needs to be validated externally. This should be ideally done with different study population prospectively to see the reproducibility of findings. 


\section{Conclusions and Recommendations}

The new CRL chart based on local data will be suitable for application in Sri Lankan setting. The new CRL chart in comparison with Intergrowth- $21^{\text {st }}$ chart showed lower SD for all gestational ages. Therefore, dispersion of data set was smaller in our study. When two charts compared using independent sample paired $\mathrm{T}$ test, there was no statistically significant difference between two sample means (p-value 0.447) and Standard deviations (p-value 0.585). Prior to generalization our Sri Lankan CRL chart needs to be validated externally.

\section{Conflicts of Interest}

The authors declare no conflicts of interest regarding the publication of this paper.

\section{References}

[1] Thilaganathan, B. and Chudleigh, T. (2004) Obstetric Ultrasound How, Why and When. 3rd Edition, Elsevier Limited, London, 30-45.

[2] Edmonds, D.K. (2012) Dewhurst's Textbook of Obstetrics \& Gynaecology. 8th Edition, Wiley-Blackwell, Hoboken, 26-32. https://doi.org/10.1002/9781119979449

[3] Robinson, H.P. (1973) Sonar Measurement of Fetal Crown-Rump Length as Means of Assessing Maturity in First Trimester of Pregnancy. British Medical Journal, 4, 28-31. https://doi.org/10.1136/bmj.4.5883.28

[4] Robinson, H.P. and Fleming, J.E. (1975) A Critical Evaluation of Sonar "Crown-Rump Length” Measurements. British Journal of Obstetrics and Gynaecology, 82, 702-710. https://doi.org/10.1111/j.1471-0528.1975.tb00710.x

[5] Hadlock, F.P., Shah, Y.P., Kanon, D.J. and Lindsey, J.V. (1992) Fetal Crown-Rump Length: Reevaluation of Relation to Menstrual Age (5 - 18 Weeks) with High-Resolution Real-Time US. Radiology, 182, 501-505. https://doi.org/10.1148/radiology.182.2.1732970

[6] Pexsters, A., Daemen, A., Bottomley, C., Van Schoubroeck, D., De Catte, L., De Moor, B., et al. (2010) New Crown-Rump Length Curve Based on over 3500 Pregnancies. Ultrasound in Obstetrics \& Gynecology, 35, 650-655. https://doi.org/10.1002/uog.7654

[7] Napolitano, R., Dhami, J., Ohuma, E.O., Ioannou, C., Conde-Agudelo, A., Kennedy, S.H., et al. (2014) Pregnancy Dating by Fetal Crown-Rump Length: A Systematic Review of Charts. British Journal of Obstetrics and Gynaecology, 121, 556-565. https://doi.org/10.1111/1471-0528.12478

[8] Sahota, D.S., Leung, T.Y., Leung, T.N., Chan, O.K. and Lau, T.K. (2009) Fetal Crown-Rump Length and Estimation of Gestational Age in an Ethnic Chinese Population. Ultrasound in Obstetrics \& Gynecology, 33, 157-160. https://doi.org/10.1002/uog.6252

[9] McLennan, A.C. and Schluter, P.J. (2008) Construction Of modern Australian First Trimester Ultrasound Dating and Growth Charts. Journal of Medical Imaging and Radiation Oncology, 52, 471-479. https://doi.org/10.1111/j.1440-1673.2008.01992.x

[10] Verburg, B.O., Steegers, E.A., De Ridder, M., Snijders, R.J., Smith, E., Hofman, A., et al. (2008) New Charts for Ultrasound Dating of Pregnancy and Assessment of Fetal Growth: Longitudinal Data from a Population-Based Cohort Study. Ultra- 
sound in Obstetrics \& Gynecology, 31, 388-396. https://doi.org/10.1002/uog.5225

[11] MacGregor, S.N., Tamura, R.K., Sabbagha, R.E., Minogue, J.P., Gibson, M.E. and Hoffman, D.I. (1987) Underestimation of Gestational Age by Conventional CrownRump Length Dating Curves. Obstetrics and Gynecology, 70, 344-348.

[12] Sladkevicius, P., Saltvedt, S., Almstrom, H., Kublickas, M., Grunewald, C. and Valentin, L. (2005) Ultrasound Dating at 12-14 Weeks of Gestation. A Prospective Cross-Validation of Established Dating Formulae in in- Vitro Fertilized Pregnancies. Ultrasound in Obstetrics \& Gynecology, 26, 504-511. https://doi.org/10.1002/uog.1993

[13] Grange, G., Pannier, E., Goffinet, F., Cabrol, D. and Zorn, J.R. (2000) Dating Biometry during the First Trimester: Accuracy of an Every-Day Practice. European Journal of Obstetrics, Gynecology, and Reproductive Biology, 88, 61-64. https://doi.org/10.1016/S0301-2115(99)00127-X

[14] Helmerhorst, F.M., Perquin, D.A., Donker, D. and Keirse, M.J. (2004) Perinatal Outcome of Singletons and Twins after Assisted Conception: A Systematic Review of Controlled Studies. British Medical Journal, 328, 261. https://doi.org/10.1136/bmj.37957.560278.EE

[15] Hansen, M., Bower, C., Milne, E., de Klerk, N. and Kurinczuk, J.J. (2005) Assisted Reproductive Technologies and the Risk of Birth Defects-A Systematic Review. Human Reproduction, 20, 328-338. https://doi.org/10.1093/humrep/deh593

[16] Hansen, M., Kurinczuk, J.J., Milne, E., de Klerk, N. and Bower, C. (2013) Assisted Reproductive Technology and Birth Defects: A Systematic Review and Meta-Analysis. Human Reproduction Update, 19, 330-53. https://doi.org/10.1093/humupd/dmt006

[17] Papageorghiou, A.T., Kennedy, S.H., Salomon, L.J., Ohuma, E.O., Cheikh Ismail, L., Barros, F.C., et al. (2014) International Standards for Early Fetal Size and Pregnancy Dating Based on Ultrasound Measurement of Crown-Rump Length in the First Trimester of Pregnancy. Ultrasound in Obstetrics \& Gynecology, 44, 641-648. https://doi.org/10.1002/uog.13448

[18] American Congress of Obstetricans and Gynaecologist (ACOG) (2014) Committee Opinion No. 611: Method for Estimating Due Date. Obstetrics \& Gynecology, 124, 863-866. https://doi.org/10.1097/01.aog.0000454932.15177.be

[19] Royston, P. and Matthews, J.N. (1991) Estimation of Reference Ranges from Normal Samples. Statistics in Medicine, 10, 691-695. https://doi.org/10.1002/sim.4780100503

[20] Altman, D.G. and Chitty, L.S. (1994) Charts of Fetal Size: 1. Methodology. British Journal of Obstetrics and Gynaecology, 101, 29-34. https://doi.org/10.1111/j.1471-0528.1994.tb13006.x

[21] Chitty, L.S., Altman, D.G., Henderson, A. and Campbell, S. (1994) Charts of Fetal size: 4. Femur Length. British Journal of Obstetrics and Gynaecology, 101, 132-135. https://doi.org/10.1111/j.1471-0528.1994.tb13078.x

[22] Department of Census and Statistics Sri Lanka (2013) Report on Population and Housing Census 2012. 